\title{
Comunicação
}

[Communication $]$

\section{Isolamento e resistência a antimicrobianos de cepas de Streptococcus spp. provenientes de rãs-touro (Lithobates catesbeianus)}

\author{
[Isolation and antimicrobial resistance of Streptococcus spp. \\ strains from bullfrog (Lithobates catesbeiana)] \\ F. Pilarski ${ }^{1}$, R.P. Schocken-Iturrino ${ }^{2}$ \\ ${ }^{1}$ Centro de Aquicultura - UNESP \\ Via de Acesso Prof. Dr. Paulo Donato Castellane s/n \\ 14884-900 - Jaboticabal, SP \\ ${ }^{2}$ Faculdade de Ciências Agrárias e Veterinárias - UNESP - Jaboticabal, SP
}

\begin{abstract}
A rã-touro, originária da América do Norte, foi introduzida no Brasil em1935 e constitui a única espécie utilizada pelos ranicultores. Apesar de ser uma espécie exótica, demonstrou boa adaptação ao clima subtropical brasileiro. Suas características zootécnicas e a qualidade de sua carne tornaram-na de grande interesse ao processamento industrial e de boa aceitação no mercado consumidor (Pasteris et al., 2006). Todavia, com a intensificação da produção, caracterizada por elevada densidade de estocagem e ração em abundância, têm sido constatado, nos últimos anos, problemas relacionados às enfermidades infecciosas, dentre elas a estreptococose.
\end{abstract}

Uma ampla variedade de cocos Gram positivo tem sido isolada de animais aquáticos, principalmente de peixes, e, com menos frequência, de rãs. A septicemia causada por Streptococcus spp. é um importante problema sanitário em sistemas de criação intensiva de rã (Suresh, 1998). Os estreptococos são bactérias Gram positivas e oportunistas, amplamente distribuídas no ambiente aquático (Bunch e Bejerano, 1997). A patogenicidade dessa bactéria está associada às condições de estresse, relacionada principalmente aos sistemas de criação não apropriados, aos manejos físico, profilático, sanitário e alimentar inadequados, às alterações na temperatura ou na luminosidade do ambiente, às alterações nos parâmetros físicos e químicos da água, bem como aos ruídos e à presença de outros animais ou pessoas (Ferreira, 2002).

Outro aspecto importante relacionado à intensificação dos sistemas de criação de rãs é o uso crescente e indiscriminado de antimicrobianos na prevenção e no tratamento de enfermidades infecciosas, o que tem gerado um aumento global da resistência bacteriana a múltiplas drogas, inclusive entre as espécies do gênero Streptococcus (Hirsch et al., 2006).

A distribuição das espécies de Streptococcus em raniculturas brasileiras e o perfil de resistência a antimicrobianos desses isolados ainda são totalmente desconhecidos. Nesse contexto, o presente estudo teve como finalidade isolar e caracterizar microbiologicamente a bactéria Streptococcus de rãs-touro provenientes de raniculturas situadas na região nordeste do estado de São Paulo, clinicamente diagnosticadas como acometidas por estreptococose, bem como avaliar a sensibilidade dos isolados a diferentes antimicrobianos.

Foram selecionadas 12 rãs touro, com peso médio de $21 \pm 2.4 \mathrm{~g}$, provenientes de dois ranários comerciais localizados na região nordeste do estado de São Paulo e clinicamente diagnosticadas com estreptococose pelo

Recebido em 3 de novembro de 2009

Aceito em 20 de setembro de 2010

E-mail: fabianap@caunesp.unesp.br 
Laboratório de Patologia de Organismos Aquáticos (LAPOA) do Centro de Aquicultura da Unesp, Caunesp. Os animais demonstravam sinais clínicos como anorexia, natação errática e circular, letargia, escurecimento da pele, petéquias e mortalidade massiva.

As rãs foram submetidas ao exame físico externo e à realização de um raspado das lesões (técnica do esfregaço) para posterior coloração com a metodologia de Gram e observação em microscópio óptico comum (100 X). Após esse procedimento, os animais foram sacrificados por meio de comoção cerebral, e assepticamente foi realizada a necropsia e coleta de amostras de rins, fígado, baço, encéfalo e líquido ascítico. Foram coletadas 60 amostras de material biológico, sendo 12 amostras de cada órgão acima relacionado.

O material foi semeado em caldo Brain Heart Infusion (BHI - Difco) em duplicata e incubado a $37^{\circ} \mathrm{C}$ durante 24 horas. Após o período de incubação, uma alíquota do caldo, semeada em ágar sangue azida, contendo $10 \mathrm{~g}$ de triptosa, $3,0 \mathrm{~g}$ de extrato de carne, 5,0g de $\mathrm{NaCl}, 0,2 \mathrm{~g}$ de azida sódica, $15 \mathrm{~g}$ de ágar e $5 \%$ de sangue de ovino desfibrinado, foi incubada a $30^{\circ} \mathrm{C}$ em atmosfera de aerofilia durante 48 horas. As colônias isoladas foram semeadas em placas de Petri contendo ágar sangue para realização do teste de hemólise. Após o período de incubação, procedeu-se à caracterização das estirpes isoladas por meio da citobacterioscopia, das características culturais, morfológicas e das provas bioquímicas.

Os isolados considerados cocos Gram positivo encontrados aos pares ou em cadeia, que apresentaram negatividade para a catalase e positividade para a fermentação da glicose, foram submetidos aos testes bioquímicos.

A susceptibilidade dos isolados a antimicrobianos foi determinada baseando-se na técnica de difusão em disco em placas de ágar Mueller-Hinton (National Committee for Clinical Laboratory Standards, 2000). As 25 estirpes isoladas - sete dos rins, três do fígado, duas do baço, 12 do encéfalo e uma do líquido abdominal
- foram submetidas ao teste de sensibilidade aos antimicrobianos: cotrimoxazol, ceftazidima, cefoxitina, eritromicina, gentamicina, amicacina, cefalotina, cefotaxima, clindamicina, cloranfenicol, oxacilina, tetraciclina, vancomicina e penicilina. As placas com os inóculos foram incubadas em estufa à temperatura de $30^{\circ} \mathrm{C}$ por 24 horas. Após esse período, os diâmetros das zonas de inibição foram mensurados e comparados com a tabela de performance padrão para testes de susceptibilidade a antimicrobianos e, então, classificados em resistentes e sensíveis.

De todas as amostras isolaram-se cepas de Streptococcus spp. Constatou-se, pela atividade hemolítica, que as cepas foram $\beta$-hemolíticas e que houve predominância da bactéria no encéfalo (Tab. 1).

Tabela 1. Número e isolados de Streptococcus spp. em 60 amostras de material biológico obtidas de rãs touro

\begin{tabular}{lccc}
\hline Material & Total & Isolados & $\%$ \\
\hline Rins & 12 & 7 & 58,33 \\
Fígado & 12 & 3 & 25,00 \\
Baço & 12 & 2 & 16,66 \\
Encéfalo & 12 & 12 & 100,00 \\
Líquido ascítico & 12 & 1 & 8,33 \\
\hline
\end{tabular}

Os esfregaços em lâmina de microscopia corados pelo método de Gram evidenciaram a presença de cocos Gram positivos agrupados em pares ou em cadeia. As colônias desenvolvidas em meio sólido apresentaram morfologia ligeiramente convexa, puntiforme e circular, acinzentada e translúcida.

As características bioquímicas encontradas para os isolamentos foram semelhantes às obtidas por outros pesquisadores para Streptococcus spp. de peixes (Shoemaker et al., 2000; Salvador et al., 2005). Todas as cepas isoladas apresentaram resultado negativo para a prova da catalase, da bile esculina, produção de $\mathrm{H}_{2} \mathrm{~S}$, hidrólise da ureia, descarboxilação da lisina, dentre outros (Tab. 2). 
Tabela 2. Características bioquímicas das cepas identificadas como pertencentes ao gênero Streptococcus

\begin{tabular}{lclc}
\hline Característica & Resposta & \multicolumn{1}{c}{ Característica } & Resposta \\
\hline Desaminação do L triptofano & + & Amido & - \\
Fermentação da glicose & + & Arabinose & - \\
Rhamnose & + & Manitol & - \\
Citrato & + & Sorbitol & - \\
Catalase & - & Lactose & - \\
Hidrólise da ureia & - & Indol & - \\
Produção de $\mathrm{H}_{2} \mathrm{~S}$ & - & Esculina & - \\
Descarboxilação da lisina & - & Motilidade & - \\
Descarboxilação da ornitina & - & Crescimento em $\mathrm{NaCl} \mathrm{6,5 \%}$ & - \\
Gás a partir da glicose & - & Crescimento a 37 $\mathrm{C}$ & + \\
Gelatina & - & & \\
\hline
\end{tabular}

A classificação dos isolados de rãs-touro demonstrou homologia dos perfis bioquímicos com a cepa referência de $S$. difficile (ND 2-22), responsável por meningoencefalite em tilápia-doNilo na região norte do estado do Paraná (Salvador et al., 2005).

O teste de sensibilidade aos antimicrobianos revelou 111 padrões de resistência (Tab. 3), e todas as estirpes de Streptococcus foram sensíveis à gentamicina e ao cloranfenicol e altamente sensíveis à cefotaxima e à vancomicina. É relevante mencionar que foram altos os padrões de resistência à cefalotina, à oxacilina, ao cotrimoxazol e à penicilina.
A bactéria Streptococcus é um patógeno emergente na piscicultura e agora também na ranicultura e já apresenta resistência a um grande número de antimicrobianos. Os resultados obtidos com relação à resistência principalmente à cefalotina, à oxacilina e à penicilina sugerem que o ambiente de criação e as rãs constituem fontes potenciais de bactérias resistentes, especialmente aos antimicrobianos acima descritos.

Tabela 3. Padrões de resistência aos antimicrobianos apresentados por estirpes $(\mathrm{n}=25)$ de Streptococcus spp. isolados em rãs-touro

\begin{tabular}{cccccc}
\hline Padrão & $\begin{array}{c}\text { Fenótipo de resistência ao } \\
\text { antimicrobiano }\end{array}$ & $\begin{array}{c}\text { Estirpes } \\
\text { resistentes }\end{array}$ & $\begin{array}{c}\text { Resistência } \\
(\%)\end{array}$ & $\begin{array}{c}\text { Estirpes } \\
\text { sensíveis }\end{array}$ & $\begin{array}{c}\text { Sensibilidade } \\
(\%)\end{array}$ \\
\hline 1 & Cotrimoxazol & 14 & 56 & 11 & 44 \\
2 & Ceftazidima & 8 & 32 & 17 & 68 \\
3 & Cefoxitina & 2 & 8,0 & 23 & 92 \\
4 & Eritromicina & 10 & 40 & 15 & 60 \\
5 & Gentamicina & 0 & 0 & 25 & 100 \\
6 & Amicacina & 12 & 48 & 13 & 52 \\
7 & Cefalotina & 16 & 64 & 9 & 36 \\
8 & Cefotaxima & 1 & 4,0 & 24 & 96 \\
9 & Clindamicina & 11 & 44 & 14 & 56 \\
10 & Cloranfenicol & 0 & 0 & 25 & 100 \\
11 & Oxacilina & 16 & 64 & 9 & 36 \\
12 & Tetraciclina & 6 & 24 & 19 & 76 \\
13 & Vancomicina & 1 & 4,0 & 24 & 96 \\
14 & Penicilina & 14 & 56 & 11 & 44 \\
\hline
\end{tabular}

Shoemaker e Klesius (1997) relataram dificuldades na utilização de antibióticos para o tratamento de infecções por Streptococcus spp., pois o patógeno pode sobreviver no interior de macrófagos, onde as drogas antimicrobianas não os alcançam. Os antibióticos podem eliminar os sinais clínicos, mas não o agente; os animais doentes não se alimentam da ração medicada e, portanto, determinam maior predisposição às linhagens do microrganismo resistentes. 
No ambiente aquático, principalmente em sistemas de criação intensiva de rãs, estas permanecem em contato com um grande número de microrganismos potencialmente patogênicos, mas, em condições normais, os animais permanecem saudáveis. Todavia, em condições estressantes, como manejo incorreto ou condições sanitárias inadequadas, as bactérias oportunistas, como o Streptococcus spp. podem tornar-se patógenos potenciais (Pasteris et al., 2006). A estreptococose é uma enfermidade que provoca grandes perdas econômicas em pisciculturas do mundo todo, e escassos são os relatos dessa enfermidade em raniculturas.

No Brasil, estudos bacteriológicos foram realizados com cepas de Streptococcus spp. principalmente em tilápias (Salvador et al., 2005). Entretanto, este é o primeiro relato do isolamento dessa bactéria em rãs-touro no estado de São Paulo.

Sabe-se que interações entre a bactéria e a pele do hospedeiro são o primeiro passo para a adesão, colonização e translocação bacteriana (Nikoskelainen et al., 2001). Neste estudo, a porta de entrada para o patógeno foram as lacerações encontradas na pele, como as petéquias, as quais revelaram distorções glandulares, que serviram para a colonização bacteriana preferencial de órgãos vitais das rãs, como os rins e o sistema nervoso (encéfalo). Estes resultados foram semelhantes aos encontrados por Salvador et al. (2005), que isolaram Streptococcus iniae de tilápias-do-Nilo com predominância da bactéria em 12 das 17 amostras de encéfalo analisadas $(70,6 \%)$.

Estreptococos são bactérias amplamente distribuídas no ambiente aquático, e sua patogenicidade está associada às condições de estresse relacionadas principalmente à qualidade da água e às condições de criação intensiva. Assim, o aumento da densidade populacional é diretamente proporcional à ocorrência de abrasões de pele nas rãs, indicando que esta é uma das principais vias de infecção, o que pode ter contribuído para a infecção massiva das rãs pela bactéria.
Os estreptococos podem sobreviver mesmo em condições ambientais adversas. Perera et al. (1997) sugeriram a existência de fonte permanente de estreptococos no meio aquático. Quando as condições são favoráveis, tais como grande quantidade de matéria orgânica, as bactérias presentes na água multiplicam-se e provocam surtos de enfermidade nos animais aquáticos.

Mauel et al. (2002) relataram um surto de estreptococose em ranários comerciais da Georgia, o qual provocou um grande número de mortalidade, fato inédito para a bactéria Streptococcus em rãs. Isso também foi observado neste trabalho, em que a mesma bactéria foi responsável pela mortalidade de $80 \%$ das rãstouro.

Embora o uso de antibióticos para o tratamento de bacterioses reduza a mortalidade, a prevenção ainda é a melhor forma de garantir a saúde do plantel, uma vez que o custo dos antimicrobianos é oneroso e muitas vezes inefetivo. A redução de agentes estressores, como densidade adequada de animais por baias e manutenção de uma boa qualidade de água, ainda é a maneira mais eficiente para evitar enfermidades, principalmente por bactérias como Streptococcus. Dessa forma, o estresse gerado pelo sistema de criação intensivo observado nos ranários estudados, principalmente com relação à elevada densidade populacional de rãs por baia, provavelmente foi o responsável pelo aumento da susceptibilidade dos animais à infecção por Streptococcus spp.

Conclui-se que a bactéria Streptococcus foi a responsável pela septicemia e meningoencefalite observadas nas rãs-touro e que os antimicrobianos cloranfenicol, gentamicina, vancomicina, cefotaxima e cefoxitina podem ser os mais indicados para o tratamento da estreptococose.

Palavras-chave: rã-touro, Streptococcus spp., isolamento, antibiograma 


\begin{abstract}
Twelve bullfrogs were selected from two commercial frog farms and clinically diagnosed as attacked by Streptococcus disease. Sixty samples were collected, and Streptococcus spp. was isolated from all bullfrog, being 12 (100\%) from the encephalus, seven from the kidneys (58.3\%), three from the liver (25\%), two from the spleen (16.6\%), and one from the ascitic liquid (8.3\%). Streptococcus $\infty$-hemolytic were isolated from all the 60 samples, which were sensible to chloramphenicol (100\%), gentamycin (100\%), vancomycin (96\%), cefotaxime (96\%), and cefoxitine (92\%).
\end{abstract}

Keywords: bullfrog, Streptococcus spp., isolation, antibiogram

\section{REFERÊNCIAS BIBLIOGRÁFICAS}

BUNCH, E.C.; BEJERANO, I. The effect of environmental factors on the susceptibility of hybrid tilapia Oreochromis niloticus $\mathrm{X}$ Oreochromis aureus to streptococcosis. Israeli J. Aquacult., v.49, p.67-76, 1997.

FERREIRA, C.M. Avaliação da toxicidade do cobre e do uso de girinos de rã-touro (Rana catesbeiana Shaw, 1802) como animais sentinelas. 2002. 117f. Tese (Doutorado) Faculdade de Medicina, Universidade de São Paulo, São Paulo, SP.

HIRSCH, D.; PEREIRA JÚNIOR, D.J.; LOGATO, P.V.R. et al. Identificação e resistência a antimicrobianos de espécies de Aeromonas móveis isoladas de peixes e ambientes aquáticos. Cien. Agrot., v.30, p.12111217, 2006.

MAUEL, M.J.; MILLER, D.L.; FRAZIER, K.S. et al. Bacterial pathogens isolated from cultured bullfrog (Rana catesbeiana). J. Vet. Diagn. Invest., v.15, p.431-433, 2002.

NIKOSKELAINEN, S.; SALMINEM, S.; BYLUND, G. et al. Characterization of the properties of human and dairy-derived probiotics for prevention of infectious diseases in fish. Appl. Environ. Microbiol., v.67, p.2430-2435, 2001.
PASTERIS, S.E.; BUHLER, M.I.; NADERMACÍAS, M.E. Microbiological and histological studies of farmed-bullfrog (Rana catesbeiana) tissues displaying red-leg syndrome. Aquaculture, v.251, p.11-18, 2006.

PERERA, R.P.; JOHNSON, S.K.; DONALD, H.L. Epizootiological aspects of Streptococcus iniae affecting tilapia in Texas. Aquaculture, v.152, p.25-33, 1997.

SALVADOR, R.; MULLER, E.E.; FREITAS, J.C. et al. Isolation and characterization of Streptococcus spp. group B in Nile tilápias (Oreochromis niloticus) reared in hapas nets and earth nurseries in the northern region of Parana State, Brazil. Cienc. Rural, v.35, p.1374-1378, 2005.

SHOEMAKER, C.; KLESIUS, P. Streptococcal disease problems and control: a review. Tilapia Aquacult., v.2, p.671-680, 1997.

SHOEMAKER, C.A.; EVANS, J.J.; KLESIUS, P.H. Density and dose: factors affecting mortality of Streptococcus iniae infected tilapia (Oreochromis niloticus). Aquaculture, v.188, p.229-235, 2000.

SURESH, A.V. Tilapia Update 1998. World Aquacult., v.30, p.8-68, 1998. 